\title{
Analysis of the Fluctuation of Chinese Crude Oil Futures- Based on GARCH-type Model
}

\author{
Hongguo Sun and Wenhui Li \\ Department of Mathematics and Finance, Hunan University of Humanities Science and Technology, Loudi, China
}

\begin{abstract}
On March 26, 2018, Chinese crude oil futures start online trading in Shanghai futures exchange, a subsidiary of Shanghai international energy trading center. Chinese crude oil futures are expected to balance the current benchmark prices of WTI and brent .This study aims at analyzing the Chinese high frequency crude oil price. In this study, GARHC-type models are used namely GARCH and TARCH for modelling the high frequency Chinese crude oil yield. It is concluded that the TARCH model performs well as compared to GARCH models. At last, the VaR of the crude oil yield in the next day is calculated for comparative analysis.
\end{abstract}

\section{Keywords-Chinese crude oil, GARCH, TARCH, ARCH-test}

\section{INTRODUCTION}

On March 26, 2018, Chinese crude oil futures start online trading in Shanghai futures exchange, a subsidiary of Shanghai international energy trading center. Since the opening week, the investment atmosphere is rational and active. Chinese crude oil futures are expected to balance the current benchmark prices of WTI and brent, which cannot truly reflect the supply and demand situation in the asia-pacific market. WTI and brent futures respectively reflect the supply and demand of crude oil in the americas and Europe, but they cannot accurately reflect the supply and demand dynamics in Asian markets.

So far, most of the research literature has focused on the international crude oil futures. Estimation has been carried out using GARCH-type models, for both the extreme downside and upside Value-at-Risks (VaR) of returns in the WTI and Brent crude oil spot markets[1]. In regime-switching models, the oil return volatility has a dynamic process whose mean is subject to shifts[2]. For WTI, however, DCC, BEKK and diagonal BEKK suggest holding crude oil futures to spot[3].some establish ARMA-GARCH model for predicting, and they proposed a new concept of interacted fluctuation to analyze the correlation of change trend of carbon price and international crude oil price[4].Some analyzed the relationship between the dollar exchange rates and the prices of two commodities, palm oil and crude oil, by using the GARCH $(1,1)$ model to examine the volatility of the exchange rates and the future prices1-Pos. of the prices of both the commodities[5]. Some used the copula based ARMA-GARCH to examine the dependence structure between the weekly prices of two commodities, namely crude oil and crude palm oil, namely crude oil and crude palm oil.It found evidence of a weak positive of two commodities price[6]. Some proposes to analyze the applicability of TVEC-Copula-DCCGARCH methodology to model crude oil volatility, it estimated an out -sample hedge during European crisis, it shows that the copula-DCC-GARCH presents a superior fit [7]. Some empirically investigate the time varying co-movements between crude oil and Indian stock market returns both at aggregate and sector level [8]. Three-time series models are used namely Box-Jenkins ARIMA (Auto-regressive Integrated Moving Average), GARCH(Generalized Auto-regressive Conditional Hetero-scedasticity) and ARIMA Kalman for modelling and forecasting the monthly crude oil price of Pakistan[9].

On the basis of previous studies, this paper uses the GARCH-type models to study the volatility characteristics of China's crude oil futures yield.

\section{GARCH MODEL}

When modeling Chinese crude oil yield, often a clustering phenomenon of yield volatility is evident. In order to describe it, Engle(1982) deve; oped the standard ARCH model. When the lag of ARCH model became too large, Bollerslev (1986) proposed the GARCH model, which is a new prediction model that is used to describe the volatility of financial data. The GARCH model can be expressed as follows:

$$
\sigma_{t}^{2}=c+\sum_{i=1}^{p} \alpha_{i} \varepsilon_{t-i}^{2}+\sum_{j=1}^{q} \beta_{j} \sigma_{t-j}^{2}
$$

Where $\quad \alpha_{i} \geq 0(i=1,2, \ldots, p), \beta_{j} \geq 0(j=1,2, \ldots, q)$, and $\sum_{i=1}^{p} \alpha_{i}+\sum_{j=1}^{q} \beta_{j}<1$, which reflects the duration of return volatility.

Meanwhile, significant leverage effect often can be seen in the volatility of crude oil price yields, which tells that the current volatile degree of returns caused by the previous crude oil price yield increase is quite asymmetric. TGARCH(Zakoian,1994) model is applied to discuss this topic, and its conditional variance can be depicted as follows:

$$
\sigma_{t}^{2}=c+\sum_{i=1}^{p} \alpha_{i} \varepsilon_{t-i}^{2}+\alpha_{0} \varepsilon_{t-1}^{2} d_{t-1}+\sum_{j=1}^{q} \beta_{j} \sigma_{t-j}^{2}
$$

Where if $\varepsilon_{t-1}<0, d_{t-1}=1$; otherwise, $d_{t-1}=0$. 


\section{EMPIRICAL ANALYSIS}

\section{A. Data and Descriptive Statistics}

This paper selects sixty minute time series for crude oil future closing prices, which is recorded as crude oil. The sample data in this paper range from April 16, 2018 to June 25,2018,a total of 419 data. All data come from Dazhihui database. Figure 1 shows that duing the period, all data experience a rising trend which means that after China's crude oil futures went public in March 26,2018, the price of crude oil futures continue to rise, it means that investors are generally bullish on China's crude oil futures. The number of participating traders has increased, and the trading volume has grown rapidly. The graph of raw data is as follows:

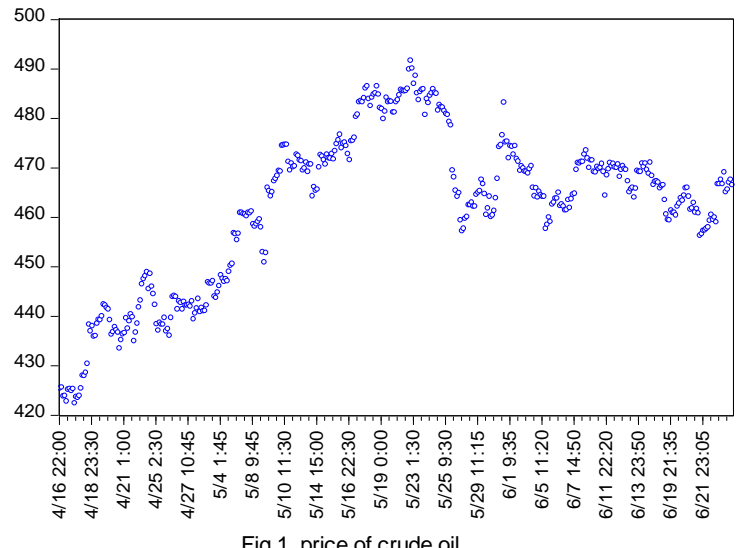

In order to eliminate the unstationary in the time series, the series of crude oil closing prices is converted into returns by taking first differenced logarithms as follows:

$$
r_{t}=100 * \ln \left(\text { crudeoil }_{t} / \text { crudeoil }_{t-1}\right)
$$

We firstly employ ADF test to determine whether the series are stable or not. It is easily to know that the raw series of crude oil futures prices is not stable, and the series of yields of crude oil futures is significant at $5 \%$ level and have passed the stationary test.

Table 1 lists descriptive statistics of data. As shown in Table 1, it can be seen from the mean value is 461.8556 , there is not bigger different compared to the maximum futures price and the minimum futures price, while the mean of the return of crude oil is $0.022064 \%$, which is bigger different compared to the maximum return and the minimum return. From the point of skewness, the raw data of crude oil is skew to the left, while the return of crude oil futures is skew to the right. From the view of kurtosis, the raw data of crude oil is 2.604282, which is not peak and fat tail, while the return of crude oil futures is 8.289205 , which render the characteristics of peak and fat tail, it means that the volatility model might be appropriate.

TABLE I. DESCRIPTIVE STATISTICS ANALYSIS OF DATA

\begin{tabular}{lll}
\hline & Crude oil & $\mathrm{r}$ \\
\hline mean & 461.8556 & 0.022064 \\
maximum & 491.7000 & 2.873511 \\
minimum & 422.4000 & -1.919688 \\
Skewness & -0.556478 & 0.460770 \\
Kurtosis & 2.604282 & 8.289205 \\
obs & 419 & 418 \\
\hline
\end{tabular}

\section{B. Estimation of GARCH Type Models}

According to the series of yield of crude oil, estimation has been carried out using GARCH-type models, based on normal distribution(N),student distribution(T) and generalized error distribution(GED).

This paper mainly use the GARCH(1,1) and TGARCH $(1,1)$ models, in which the random error terms obey normal distribution, T distribution and generalized error distribution.

TABLE II. THE FITTING RESULTS UNDER EVERY RANDOM ERROR DISTRIBUTION

\begin{tabular}{lllll}
\hline & GARCH(0,1)-N & GARCH(0,1)-T & GARCH(0,1)-GED & TARCH(1,1)-N \\
\hline$C$ & 0.030478 & 0.046636 & 0.030164 & 0.199568 \\
& $(1.005968)$ & $(0.552578)$ & $(0.463433)$ & 0.179125 \\
$\alpha_{1}$ & & & & $(2.585571)$ \\
$\alpha_{0}$ & & & & -0.216988 \\
$\beta$ & & & & $(-2.944445)$ \\
ARCH(P-value) & 0.857764 & 0.822576 & 0.857419 & \\
AIC & $(6.009897)$ & $(2.647462)$ & $(2.761443)$ & 0.7489 \\
SC & 1.9888 & 0.9900 & 0.9890 & 1.289557 \\
VaR(1) & 1.313417 & 1.103439 & 1.089978 & 1.318520 \\
\end{tabular}

TABLE 2 shows that, obviously, the variables of the four models passed the test at the level of $1 \%$.From the point of ARCH test, there is no heteroscedasticity. According to the AIC and the SC, the GARCH(0,1)-GED is the best model, but other models are also acceptable, especially the TARCH(1,1)-N model. From the table3, there are some results as follows:

Firstly, according to the GARCH(0,1)-N, the coefficient of the variance is 0.857764 in the first lag period, which has a large impact to the current variance, and has a long duration, according to the $\operatorname{GARCH}(0,1)-\mathrm{T}$, the coefficient of the variance is 0.822576 in the first lag period, according to the GARCH(0,1)-GED, the coefficient of the variance is 0.857419 in the first lag period, it can be seen that the coefficients in the first lag period of the variance three model have small difference.

Secondly, according to the TARCH $(1,1)-\mathrm{N}$, positive and negative shocks have different effects, the positive impact 
coefficient is 0.179125 , while the negative impact coefficient is -0.037863 , which reflects the asymmetry .

At last, using the four models, it calculate the risk value at $5 \%$ level for the next day, where the initial asset is unit to 1.It shows that the VaR of TARCH(1,1)-Normal is the lowest, and the VaR of GARCH $(0,1)-T$ is the highest.

\section{CONCLUSIONS}

This paper studies the characteristics of China's crude oil futures yield fluctuation based on high-frequency data, the results show that, first, the variation of China's crude oil futures yield in current hysteresis mainly is affected by itself in the first lag period, the influence coefficient is bigger, and the influence has long time effect; second, China's crude oil futures yield in current hysteresis is affected by random error in the first lag period, and the impact of the positive and negative effects are different. Because of China's crude oil futures just listed, its trend is affected by many unknown factors, so we should pay more attention to the related factors of the domestic policy, the international crude oil futures trading and Opec, which can make Chinese crude oil futures accurately reflect the supply and demand dynamics in Asian markets.

\section{REFERENCES}

[1] Fan, Ying ; Zhang, Yue-Jun ; Tsai, Hsien-Tang ; Wei, Yi-Ming . Estimating 'Value at Risk' of crude oil price and its spillover effect using the GED-GARCH approach. Energy Economics, vol 30, n 6, pp. 3156-3171, November 2008

[2] Cuicui Luo ; Seco, L.A. ; Haofei Wang ; Desheng Dash Wu . Risk modeling in crude oil market: a comparison of Markov switching and GARCH models. Kybernetes, vol 39, n 5, pp750-69, 2010

[3] Chang, Chia-Lin; McAleer, Michael; Tansuchat, Roengchai . Crude oil hedging strategies using dynamic multivariate GARCH.Energy Economics, vol 33, n 5, pp 912-923, September 2011

[4] Zou, Xiaohua ; Tian, Lixin . Carbon price and international crude oil price fluctuations analysis based on ARMA_GARCH model. International Journal of Earth Sciences and Engineering, vol 7, n 6, pp. 2588-2593, 2014

[5] Kiatmanaroch, Teera ; Sriboonchitta, Songsak . Relationship between exchange rates, palm oil prices, and crude oil prices: A vine copula based GARCH approach. Advances in Intelligent Systems and Computing, v ol251,p p 399-413, 2014

[6] Kiatmanaroch, T. ; Puarattanaarunkorn, O.; Autchariyapanitkul, K. ; Sriboonchitta, S. Volatility Linkages Between Price Returns of Crude Oil and Crude Palm Oil in the ASEAN Region: A Copula Based GARCH Approach. Integrated Uncertainty in Knowledge Modelling and Decision Making. 4th International Symposium, IUKM, pp.428-39, 2015

[7] Souza Block, A. ; Brutti Righi, M. Crude oil market dynamics through TVEC-Copula-DCC-GARCH models: improving the variance reduction of hedging strategies. WSEAS Transactions on Business and Economics, v ol12, p p.388-99, 2015;

[8] Singhal, Shelly ; Ghosh, Sajal .Returns and volatility linkages between international crude oil price, metal and other stock indices in India: Evidence from VAR-DCC-GARCH models.Resources Policy, vol50, pp. 276-288, December 1, 2016

[9] Aamir, M. ; Shabri, A. Modelling and forecasting monthly crude oil price of Pakistan: A comparative study of ARIMA, GARCH and ARIMA Kalman model[J]. AIP Conference Proceedings, vol1750, pp. 7 , 21 June 2016. 